\title{
Team Identification and Negotiation: A Mediated-Moderation Model of Constraints, Motivation, and Sport Consumption
}

\author{
Kevin K. Byon, Carolina Alves de Lima Salge, Thomas A. Baker III, and Charles W. Jones
}

Kevin K. Byon, PhD, is an associate professor in the Department of Kinesiology at Indiana University Bloomington. His research interests include sport marketing, sport consumer behavior, and relationship marketing in sport.

Carolina Alves de Lima Salge, PhD, is an assistant professor in the Department of Management Information Systems at the University of Georgia's Terry College of Business. Her research interests include the use of bots and cyborgs for digital and the ethics surrounding their use.

Thomas A. Baker III, PhD, is an associate professor in the Department of Kinesiology at the University of Georgia. His research interests include legal issues concerning brand image, application of law to brand equity, image rights, brand equity, advertising regulations and social media, and sexual violence in youth sports.

Charles W. Jones, PhD, is an assistant professor in the Department of Sport, Exercise, Recreation, and Kinesiology at East Tennessee State University. His research interests include sport marketing and sport consumer behavior, primarily in the context of collegiate athletics and recurring mega sport events.

\begin{abstract}
The purpose of the current study was to examine (a) the mediating effect of negotiation on the relationship between fans' motivations and constraints to consume sport and to (b) investigate the moderating role of team identification in a sport consumption model of motivation, constraints, and negotiation. Using two datasets from various college athletics stakeholders (i.e., students, alumni, and non-college associated fans) at a large university in the southeastern United States. Our analyses using structural equation modeling show that negotiation mediates the relationship between motivation and sport consumption for both diehard and fair-weather fans. We also find that negotiation mediates the relationship between constraints and sport consumption with the effect being significant for fair-weather fans only.

Our study sheds light on sport consumption as it relates to fans' motivation to negotiate constraints in order to consume sport. Specifically, we extend current understanding on how different fans negotiate constraints to consume sport. Marketers can use our findings to design campaigns that focus on providing different fans with a variety of incentives to consume sport.
\end{abstract}

Keywords: sport consumption, constraints, motivation, team identification, negotiation

DOI: http://doi.org/10.32731/SMQ.294.122020.04

Consider an individual who is a die-hard fan of a sport team-e.g., someone with great interest in the team in both bad and good times (Wann \& Branscombe, 1993) - who is also a healthy and popular college student. This student is invited by a friend to go to an upcoming match in a city that is 200 miles from campus. Assume the individual wants to go (because he or she is a die-hard fan), but money is a constraint. The person is likely to choose one of the three options: (1) accept the invitation (Drakou et al., 2008) and worry about money when the need for it next arises, (2) decline the invitation because money is a constraint, or (3) find a way to raise money to attend the game. If the pros and cons are weighted as to maximize utility level, option (3) becomes the most attractive choice for this person because maximum utility is acquired-in 
options (1) and (2), some level of dissatisfaction is encountered (money- or enjoyment-wise). This hypothetical example is analytically useful because it shows us that negotiation, defined as specific resources or strategies people use to consume a particular good or service (e.g., attend a football ${ }^{1}$ game), is probably a key variable affecting sport consumption when both constraints-i.e., anything inhibiting or reducing a person's likelihood of consuming a particular good or service (Crawford et al., 1991) — and motivations-i.e., the desires associated with consuming a particular good or service-coexist.

Although our example included a die-hard fan, we assert that that negotiation (or the lack thereof) also matters for fair-weather fans-e.g., those who only show great interest in the team during good times (Wann \& Branscombe, 1993). If, for instance, our hypothetical scenario involved a fair-weather fan instead of a die-hard one, the most attractive choice would likely be different than option (3) because fair-weather fans are not highly-identified with their favorite team (Bodet \& Bernache-Assollant, 2011; Funk \& James, 2006) and are therefore less likely to attend games when lack of money is a constraint. This is especially true if the game happens to occur during a time in which the team is performing poorly. It is therefore logical to assume that the reaction to negotiation is different for different fans, and thus their consumption behaviors are also likely to be different based on their level of team identification.

Our position on the role of negotiation draws support from studies that examined the concept in leisure contexts (e.g., Hubbard \& Mannell, 2001; Jackson et al., 1993). From this line of work, we know that people who engage in negotiation are more likely to participate in leisure activities (e.g., attending a sport event) than those who do not (Hubbard \& Mannell, 2001). In regard to sport, we also know that constraints decrease consumption (Alexandris \& Carroll, 1997; Trail \& Kim, 2011) while motivation does the opposite (Fink et al., 2002).

What we do not know is how, and to what extent, negotiation is dependent on the relative strength of and interactions between constraints of consuming sport and motivations for such consumption. In addition, we do not know how team identification influences the way in which different fans negotiate constraints to consume sport. For example, does negotiation mediate the relationship of both constraints and motivation to sport consumption for both die-hard and fair-weather fans, or does it only mediate one of the relationships

1 We use the term football to refer to American football, not European soccer. just for one type of fan? In this study, we attempt to answer these questions by empirically analyzing both the mediating effect of negotiation and the moderating effect of team identification in a sport consumption model of constraints and motivation.

We specifically ask two questions. First, is negotiation a key construct mediating fans' motivations and constraints to consume sport? Second, what is the role of team identification in a sport consumption model of motivation, constraints, and negotiation? Negotiation and sport consumption disparities arising from fan type (i.e., die-hard vs. fair-weather) in the presence of motivations and constraints is not well-documented in the literature. Efforts to negotiate depend not only on the balancing of motivations and constraints but also on the level of identification fans have with their favorite teams. Thus, negotiation represents a construct that can either increase or reduce sport consumption. Anchoring our expectations in the constraints-effect-mitigation model (Hubbard \& Mannell, 2001), we suggest that fair-weather fans are motivated and therefore likely to negotiate constraints to consume sport when their teams are performing well. Because all fans in our sample are somewhat motivated to support their team (i.e., they show interest in the team), their willingness to negotiate constraints is likely high (Jones et al., 2017; Loucks-Atkinson \& Mannell, 2007). Hence, we posit that negotiation mediates the relationship between motivation and sport consumption for both die-hard and fair-weather fans. Our hypotheses are tested with two datasets collected from various college athletics stakeholders at a large university in the southeastern United States.

Our analyses using structural equation modeling show that negotiation mediates the relationship between motivation and sport consumption for both die-hard and fair-weather fans. We also find that negotiation mediates the relationship between constraints and sport consumption with the effect being significant for fair-weather fans only. We contribute to the sport marketing literature by extending current understanding on how different fans negotiate constraints as to consume sport. Sport marketers can use our findings to design campaigns that focus on providing different fans with a variety of incentives to consume sport.

The two proceeding sections to this article describe the theoretical foundation for our study. The first of the two sections introduces the reader to the constraints-effect-mitigation model. The second section describes our research models and hypotheses that were tested in the current study. Following the two theoretical sections is a description of our methodology in which we detail the sample, instruments, data 
collection procedures, and data analyses used. The article concludes with a discussion of our findings together with theoretical and practical implications.

\section{The Constraints-Effect-Mitigation Model}

Our models were developed based on the constraints-effect-mitigation model (Hubbard \& Mannell, 2011), which denotes the role of negotiation in influencing leisure participation behavior in the presence of motivations and constraints. Using the constraints-effect-mitigation model as the theoretical framework, we proposed two models explicating how die-hard and fair-weather fans form sport consumption decision-making through negotiating constraints and motivations.

The constraints-effect-mitigation model (Hubbard \& Mannell, 2001) explains the determinants of leisure participation in a general form. According to the theory, people's leisure participation depends on their negotiation of constraints, which are weighted against motivations to participate. Yet, "motivation to participate in a leisure activity may act directly and independently of constraint and negotiation to influence level of participation positively by encouraging greater use of negotiation resources or strategies" (Hubbard \& Mannell, 2001, p. 147). A major assumption of the model is that constraints exist at three levels (i.e., intrapersonal, interpersonal, and structural) and must be sequentially minimized for participation to take place. Though the direct impact of constraints on participation is intuitively assumed to be negative, the theory suggests that constraints can also have a positive effect on participation through negotiation. It predicts that constraints trigger negotiation efforts and that negotiation, in turn, can lead to participation by outweighing the negative influence imposed by constraints through motivation to participate. Thus, the overall outcome is not always intuitive because constraints can both inhibit or enable participation (Hubbard \& Mannell, 2001). We based the constraints-effect-mitigation model to develop two different pathways via which highly and lowly identified fans reach their decision to consume sport in the presence of constraints and motivations.

\section{Research Models}

Figure 1 shows Model 1, which relates the antecedents of sport consumption. More specifically, it specifies a mediated-moderation model where the relationship between motivation and sport consumption is positively mediated by negotiation-the higher a fan's motivation to consume sport, the higher the likelihood that he or she will engage in negotiation efforts-and the relationship between motivation and negotiation is moderated by team identification. Because the model illustrates a mediation-i.e., it proposes that the total effect of both motivation and constraints on sport consumption is accounted for by negotiation-we expect the moderating effect of team identification to influence consumption as well. That is, we hypothesize that the mediating effect of negotiation is likely to significantly vary for each fan (i.e., die-hard vs fair-weather). Figure 2 illustrates Model 2, which also relates the antecedents of sport consumption. However, Figure 2 only specifies a mediated-moderation effect for motivation. Constraints are hypothesized to have a negative direct effect on sport consumption. Yet, team identification is expected to moderate the relationship between constraints and sport consumption, where fair-weather fans are expected to be less constrained than die-hard fans given the fact that they are less attached to the team.

\section{Sport Consumption}

We define sport consumption as the extent to which fans consider consuming sport by attending stadium games, using media, and purchasing licensed merchandise (Kim \& Trail, 2011). Our multi-dimensional approach is appropriate because our goal is to capture a more holistic operationalization of the construct. We therefore measure sport consumption as a composite score encompassing measures of stadium attendance, media usage, and the purchase of licensed merchandise (Kim \& Trail, 2011). Attendance focuses on the number of games attended. Media usage assesses whether fans watched games on TV or the internet and how frequently they visited websites for team information. Lastly, licensed merchandise evaluates the frequency of overall fan purchase of team licensed merchandise items.

\section{Hypotheses Development (Model 1)}

Drawing on the constraints-effect-mitigation model, we suggest that motivation, constraints, and negotiation are interrelated factors impacting the consumption of sport. Higher motivation should increase the willingness to negotiate constraints (Jones et al., 2017; Loucks-Atkinson \& Mannell, 2007), reinforce pleasures that result from sport involvement (Harris, 1973), raise fan entertainment and achievement, and lower stress levels (Sloan, 1989). In the context of leisure, scholars allude to the existence of dominant motivating factor(s) either in perceiving or overcoming constraints (Crawford et al., 1991). This concept is called strength of motivation, and it has been empirically supported in a variety of contexts (e.g., Alexandris et al., 2011; Carroll \& Alexandris, 1997; Jones et al., 2017). For instance, Carroll and Alexandris (1997) found strength of motivation to be negatively related to constraints 
dimensions such as lack of interest, individual/psychological, time, lack of knowledge, and lack of partners

In the context of spectator sport consumption and its relation to constraints and motivation, three motivators were particularly identified to be essential for when predicting stadium attendance: team achievement, escape, and drama (Kim \& Trail, 2010). Although there are many motivators that have been identified to explain sport consumption (Trail \& James, 2012), these three motivating factors were empirically verified over a large number of motivators that explain a large amount of variance in sport consumption (Kim \& Trail, 2010).

Past research in leisure and sport indicates that motivation interacts with other factors such as constraints and negotiation to explain leisure and sport consumption behavior (e.g., Alexandris et al., 2011; Hubbard \& Mannell, 2011; Jackson et al., 1993; Jones et al., 2017). Constraints should significantly decrease sport consumption yet trigger the practice of negotiation at the same time (Hubbard \& Mannell, 2001). This, in turn, might increase consumption because negotiation efforts may outweigh the negative influence of constraints on consumption (Hubbard \& Mannell, 2001; Jones et al., 2017; Loucks-Atkinson \& Mannell, 2007; White, 2008). Therefore, constraints should lead diehard fans to negotiate, and the execution of negotiation should positively influence sport consumption. Thus:

H1a: The greater the motivations to consume sport, the greater chances for fans to engage in negotiation.

H2a: The greater the constraints to consume sport, the greater chances for die-hard fans to engage in negotiation.

H3a: The greater the negotiation to consume sport, the greater chances for fans to engage in sport consumption.

H4a: Negotiation would mediate the relationship between motivations and constraints to sport consumption.

\section{Moderating Effects of Team Identification (Model 1)}

Past research shows that fair-weather fans are less knowledgeable and also less attached to a team when compared to die-hard fans (Fink et al., 2002). Additionally, they only show support during good times (Murrell \& Dietz, 1992). In contrast, die-hard fans are loyal and always motivated to consume sport (Carroll \& Alexandris, 1997; Jun \& Kyle, 2011; Loucks-Atkinson \& Mannell, 2007; Petrick et al., 2001). Given past research findings, we expect die-hard fans to be more prone to negotiate constraints when compared to fair-weather fans. Yet, this is not to say that fair-weather fans are never likely to negotiate constraints; in fact, we present the possibility that during good times, fair-weather fans might strongly support teams. This expectation is supported by social identity theory (Tajfel \& Turner, 1985). According to the theory, people label themselves and others as belonging to different social groups, where membership is defined as their social identity. This identity is often used to enhance ones' self-esteem, as members are likely to evaluate the group to which they belong more favorably while evaluating the out-group more negatively. In our case, fair-weather fans are likely to over-emphasize their association with the team during good times because they aim to enhance their own self-esteem. In bad times, however, these fans are likely to abandon the team because losses do not enhance individuals' own self-esteem.

Social identity theory also posits that belonging to a group is important because it provides a way for individuals to categorize themselves with others who are similar and define a relationship to a specific other person (Tajfel \& Turner, 1985). Applying these ideas to our context implies that fair-weather fans do not categorize themselves in the same group as die-hard fans during bad times. Hence, in order to belong to the in-group during good times, fair-weather fans might overly support the team as a way to compensate for the lack of support during bad times. The need to overly support teams in good times might motivate fair-weather fans to negotiate more constraints when compared to die-hard fans. Because the team under investigation exceeded fans' expectations in terms of season finale success $^{2}$, we hypothesize the following:

$H 5 a$ : Team identification would moderate the relationship between motivation and negotiation, where fair-weather fans are more expected to engage in negotiation.

H6a: Team identification would moderate the relationship between constraints and negotiation, where fair-weather fans are more expected to engage in negotiation.

\section{Model 2}

Although multiple studies have found that negotiation mediates motivation (Hubbard \& Mannell, 2001; Son, Mowen, Kerstetter et al., 2008), only Hubbard and Mannell (2001) showed that negotiation mediates constraints to participation-Son, Kerstetter, and Mowen (2008), for example, found that negotiation does not account for the mediation between constraints and overall participation. Just because Hubbard and Mannell (2001) retained the constraints-effect-mitigation model, it does not necessarily mean that their model is the best one available. This might just be one of many

\footnotetext{
2 The team under their investigation in the current study had a slow start but finished strong by winning its own conference division and, therefore, playing in the conference championship game for the first time in six years. The team also defeated all of its major rivals.
} 


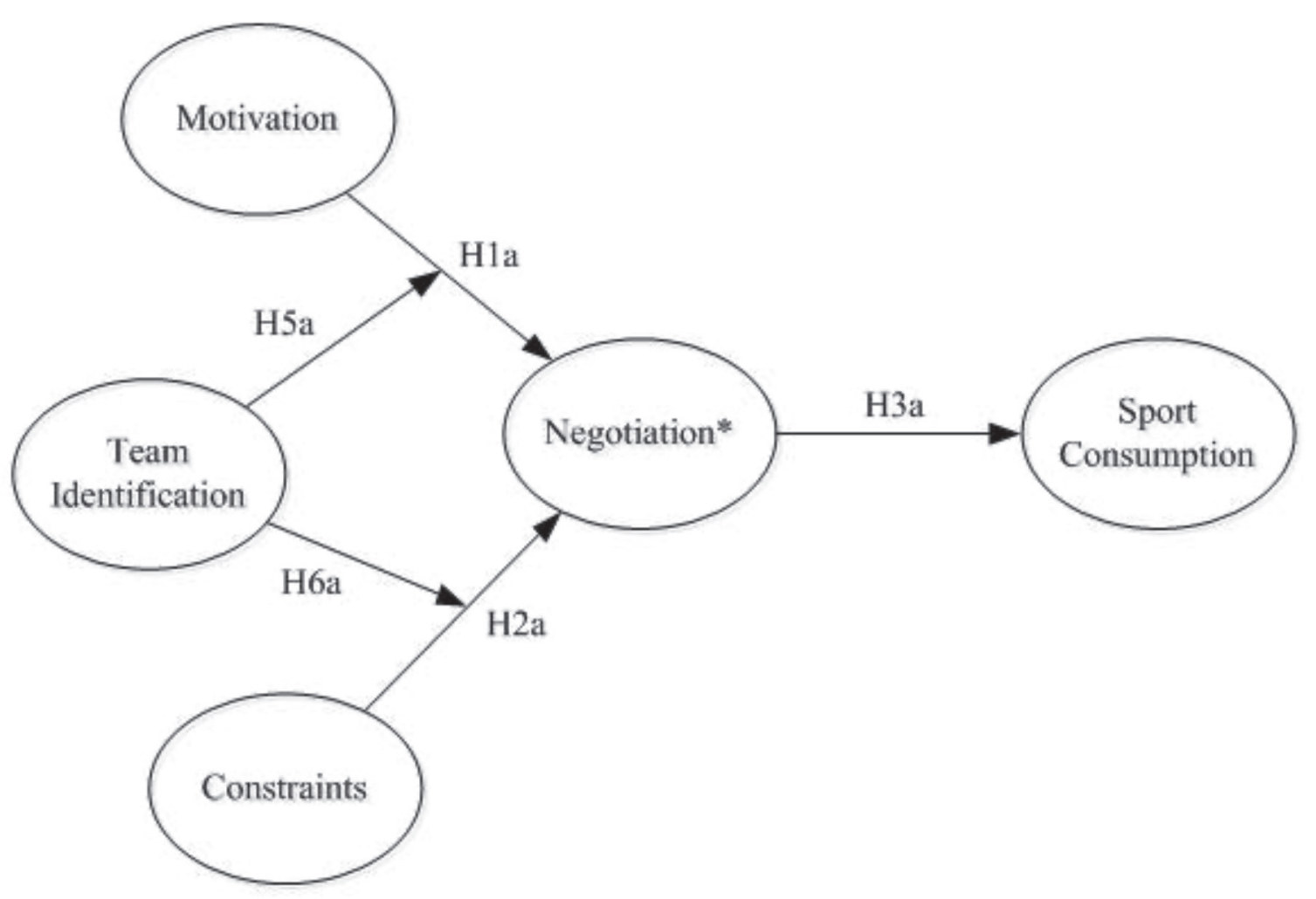

${ }^{*} \mathrm{H} 4 \mathrm{a}$ : Negotiation will fully mediate the relationship between motivation and constraints to sport consumption

Figure 1. Model 1

models that fit the data well (Vandenberg \& Grelle, 2009). Not only that, but it is also important to consider alternative models (Hershberger, 2004; Vandenberg $\&$ Grelle, 2009). We believe there is a need to propose two models given existing contradictory findings in the literature. Model 2 is based on research findings by Son, Kerstetter, Mowen et al. (2008). It has been theorized in Model 1 that motivated fans are more likely to engage in negotiation and therefore negotiation will mediate the relationship between motivation and sport consumption. The same assumptions hold for Model 2; however, Model 2 also assumes that constraints will diminish participation but not trigger negotiation. This, in turn, might only result in a negative influence of constraints in sport consumption. Thus, the following hypotheses are proposed:

$H 1 b$ : The greater the motivations to consume sport, the greater chances for fans to engage in negotiation.

$H 2 b$ : The greater the constraints to consume sport, the greater chances that fans will not consume sport.

$H 3 b$ : The greater the negotiation to consume sport, the greater chances for fans to engage in sport consumption.
$H 4 b$ : Negotiation would mediate the relationship between motivation and sport consumption.

Moderating Effects of Team Identification (Model 2) In Model 1, we theorize that team identification would moderate the relationship between motivation and negotiation, where fair-weather fans would be more motivated and therefore more likely to negotiate in order to consume sport. The same assumption holds for Model 2. Additionally, we theorize that team identification would moderate the relationship between constraints and sport consumption. More specifically, we posit that fair-weather fans are expected to be less constrained to consume sport because of their need to overly support a team during good times. Thus, the following hypotheses are posited:

$H 5 b$ : Team identification would moderate the relationship between motivation and negotiation, where fair-weather fans are more expected to engage in negotiation.

H6b: Team identification would moderate the relationship between constraints and sport consumption, where fair-weather fans are expected to be less constrained. 


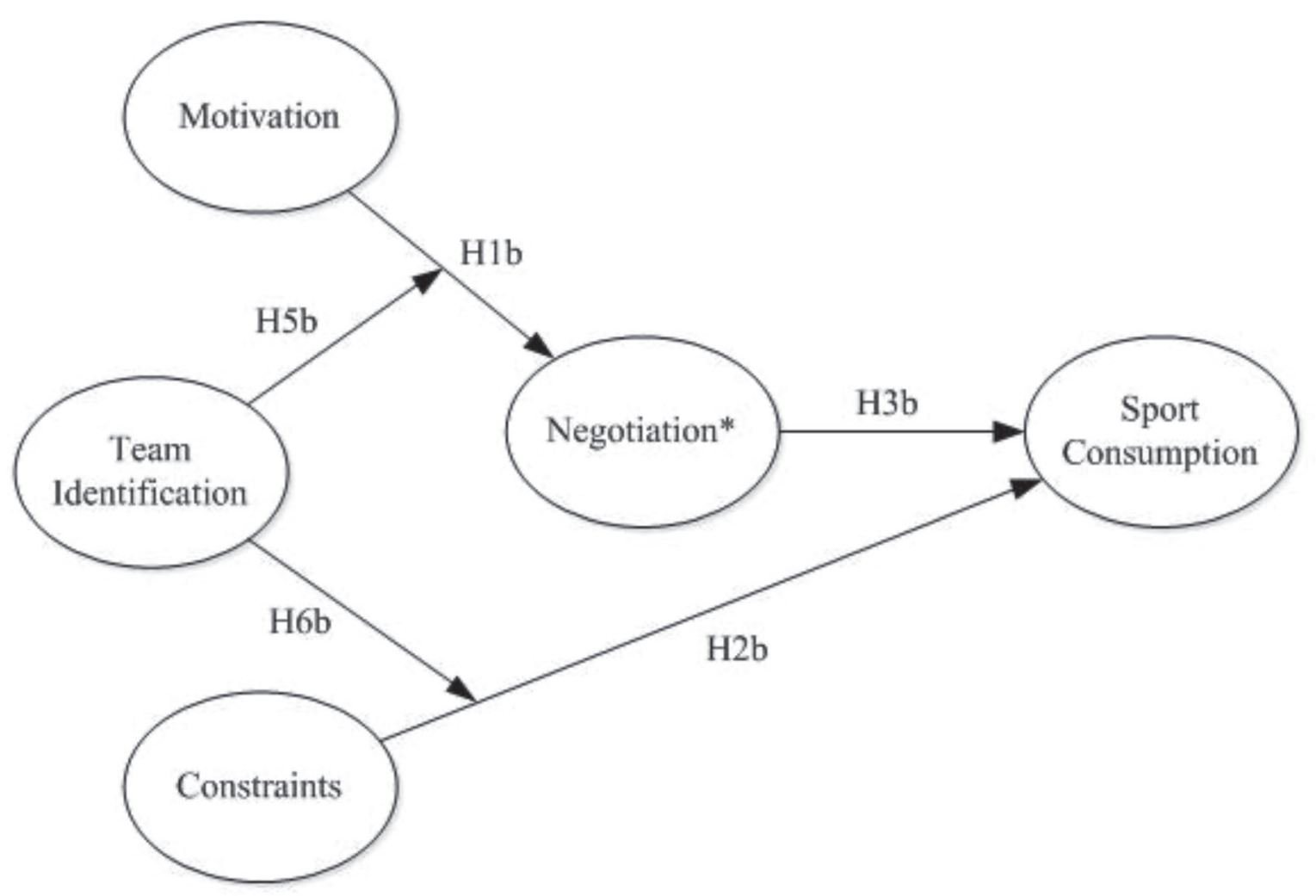

*H4b: Negotiation will fully mediate the relationship between motivation to sport consumption

Figure 2. Model 2

\section{Method}

\section{Sample and Data Collection Procedures}

We collected data using an online survey to measure all variables from the perspective of the sport consumer. A first email was sent to 451 students who were taking courses in sport management, followed by a reminder email after two weeks. Respondents were first prompted with an online consent form that emphasized the purpose of the study. We provided written instructions in all sections, and the questionnaire was administrated as follows. Parts 1 and 2 asked participants' general questions about current and future sport consumption; part 3 asked participants to indicate how well statements best describe their opinion towards their university's college football team; parts 4 through 7 asked participants the extent to which they agree with statements describing conditions that may have limited their current stadium attendance, usage of media, and purchase of licensed merchandise; and part 8 asked participants demographic questions.
The two waves of the survey administration resulted in a total of 372 responses, for an overall response rate of $82.5 \%$. Of the 372 responses received, we retained a final usable sample of 322 after discarding 50 responses via listwise deletion due to excessive missing information. Most students were financially supported by their parents (46.8\%). Almost 20\% of respondents were freshmen and sophomores in college (5\% and $12.4 \%$, respectively), while over $50 \%$ of the sample represented either juniors or seniors $(20.2 \%$ and $31.4 \%$, respectively). Of the remaining respondents, only $2.5 \%$ were graduates students, $10.2 \%$ were alumni, and $17.4 \%$ were non-students. On average, $77.3 \%$ respondents were White-non-Hispanic, 14\% were Black/African American, 3.1\% were Asian-Pacific Islander, 2.5\% were of mixed race, and the remaining $1.8 \%$ were either Native American (.9\%) or Hispanic (.9\%).

We assessed nonresponse bias by comparing data from the first wave with the second wave (Armstrong \& Overton, 1977). The final sample included $24.5 \%$ of the responses in the first wave, and the second wave included $75.5 \%$. Analysis of variance (ANOVA) tests revealed 
no significant differences between the two groups on any of the independent/mediating variables, suggesting that nonresponse bias was not a problem in our data.

\section{Measures}

We operationalized all variables using multi-item reflective measures. Motivation was measured using nine items related to team achievement, escape, and drama adapted from Kim and Trail (2010). In their study, team achievement was measured as lack of success because the team under their investigation had the second worst record in their conference. However, the team examined here had the third best record standing in a Football Bowl Champion (FBC) conference during the data collection. Thus, we examined team achievement as a motivator. Constraints were measured using 38 items related to intrapersonal, interpersonal, and structural constraints. Negotiation was also measured using 24 items related to time management, interpersonal coordination, and financial resources. Both constraints and negotiation scale items were adapted from Hubbard and Mannell's (2001) scale. Team identification was measured using five items adopted from the scales of Trail and James (2001) and Wann and Branscombe (1993). Sport consumption was assessed using six items related to stadium attendance, media usage, and purchase of licensed merchandise (Kim et al., 2011). All scale items were measured on a 5-point Likert type scale, ranging from 1 = "strongly disagree" to 5 = "strongly agree" (see Appendix for a complete list of items). Lastly, we assessed sociodemographic information such as gender, race, income, and school year.

\section{Content Validity}

We adapted existing measures to develop our questionnaire, which was refined through a pilot-test with college students at a major university in the southeastern United States. We relied on a widespread review of the existing literature as well as on conversations with research experts, especially from the leisure constraints field to develop the preliminary instrument. We also submitted the instrument to a panel of four experts for content validity testing. The panel included four university professors in sport management and leisure. Each panel member was asked to examine the overall content of the items under each of the factors in terms of their relevance, clarity, and representativeness. Following the feedback of the panel members, changes were made to improve the content of the preliminary questionnaire.

\section{Results}

\section{Measurement Model}

For the data analyses, composite scores were created for all multi-item measures (i.e., constraints, motivation, negotiation, team identification, and sport consumption). The decision was made due to the following considerations: (a) estimating a model with 50 or more items ( 88 items in the study) via covariance-based confirmatory factor analysis (CFA) and structural equation modeling (SEM) is difficult to estimate (Hair et al., 2010), and (b) the sample size $(N=321)$ would be too small to estimate a large number of variables in the current study. A CFA was performed using AMOS. Assumptions of outlier and linearity were assessed by examining the scatterplot and the Mahalanobis distance $\left(D^{\wedge} 2\right)$ values with chi-squares for the dataset. The graph yielded a straight line, suggesting linearity (Hair et al., 2010). The Mahalanobis distance method identified one outlier, which was deleted from the sample, resulting in the final sample of 321. A CFA with maximum likelihood (ML) estimation resulted in a Mardia's kurtosis value of 156.69 , indicating that multivariate normality was violated (Mardia, 1970). In order to adjust the multivariate non-normality, we performed bootstrapping by setting the number of bootstrapping sample to 1000 based on the recommendation by Hancock and Nevitt (1999). The bootstrapping procedure yields robust standard errors for the estimated coefficients, solving for the multivariate normality issue (Byrne, 2009). Given that we corrected for multivariate normality, the CFA displayed adequate fit indices $\left(\chi_{(48)}^{2}=157.56, \chi^{2} / \mathrm{df}=3.28\right.$; $\mathrm{CFI}=.97$; RMSEA $=.084$ [confidence interval $=.070$ to $.099]$; TLI $=.95$; and SRMR $=.05$ ).

To examine psychometric properties, we assessed reliability, convergent, and discriminant validity for all constructs. Composite reliability and Cronbach's alpha for each factor exceeded the suggested minimum of 80 (Hair et al., 2010; Nunnally, 1978). Average variance extracted (AVE) values for each latent construct also exceeded (a) the suggested minimum value of .50 and (b) the squared correlation between construct pairs ${ }^{3}$ (Fornell \& Larcker, 1981). For convergent validity, we found that all indicators were statistically significant and loaded high $(>0.71)$ on their respective constructs. Therefore, both discriminant and convergent validity were established in the measurement model (Table 1).

\section{Structural Equation Modeling}

An SEM was used to examine the proposed models. Model 1 shows adequate fit indices $\left(\chi_{(115)}^{2}=411.15, \chi^{2} /\right.$ $\mathrm{df}=3.92 ; \mathrm{CFI}=.90 ; \mathrm{RMSEA}=.09$ [confidence interval $=.08$ to .10$]$; TLI $=.93$; and SRMR $=.07$ ). Based on the results, it was found that motivation explains $55.4 \%$ of

\footnotetext{
3 The largest correlation shown in this model was .71 (between negotiation and sport consumption), which, if squared, equals .51. Because .51 is smaller than the lowest AVE value, which was .57 (sport consumption), one can conclude that this model reached discriminant validity.
} 
Table 1. The Confirmatory Factor Analysis Results

\begin{tabular}{llrrrrrr}
\hline \multicolumn{1}{c}{ Observed Variable } & Latent Construct & \multicolumn{1}{c}{$\boldsymbol{\lambda}$} & \multicolumn{1}{c}{ B } & SE & AVE & CR & $\boldsymbol{\alpha}$ \\
\hline Team Achievement & Motivation & .91 & 1.00 & & .81 & .93 & .95 \\
Escape & Motivation & .86 & .94 & .04 & & & \\
Drama & Motivation & .93 & 1.00 & .04 & & & \\
Interpersonal Coordination & Negotiation & .96 & 1.00 & & .88 & .92 & .96 \\
Time Management & Negotiation & .95 & .92 & .03 & & & \\
Financial & Negotiation & .91 & .56 & .02 & & & \\
Intrapersonal Constraints & Constraints & .89 & 1.00 & & .78 & .95 & .96 \\
Interpersonal Constraints & Constraints & .97 & 1.17 & .05 & & & \\
Structural Constraints & Constraints & .79 & 1.35 & .07 & & & \\
Attendance & Sport Consumption & .76 & 1.00 & & .57 & .86 & .91 \\
Media & Sport Consumption & .80 & 1.33 & .01 & & & \\
Licensed Merchandise & Sport Consumption & .71 & .50 & .04 & & & \\
Team ID 1 & Team Identification & .95 & 1.00 & & & & \\
Team ID 2 & Team Identification & .96 & 1.02 & .03 & & & \\
Team ID 3 & Team Identification & .96 & & & \\
Team ID 4 & Team Identification & .95 & 1.04 & .03 & .85 & .97 & \\
Team ID 5 & Team Identification & .90 & 1.03 & .04 & & & \\
& & .84 & .95 & .04 & & & \\
\hline & & & & & & &
\end{tabular}

the variation in negotiation. Motivation, constraints, and negotiation together explain $56.8 \%$ of the variance in sport consumption. Consequently, our study confirms that negotiation significantly contributes to variations in sport consumption. In fact, negotiation was found to have a strong relationship with sport consumption $(\beta=.67, p<.05)$. In Model 1 , we did not find a significant relationship between constraints and negotiation $(\beta=.011, p>.05)$.

Model 2 illustrates adequate fit indices as well $\left(\chi_{(108)}^{2}\right.$ $=414.386, \chi^{2} / \mathrm{df}=3.84 ; \mathrm{CFI}=.90 ; \mathrm{RMSEA}=.094$ [ confidence interval $=.085$ to .100 ]; TLI $=.93$; and SRMR $=.075)$. The variance in the dependent variables does not change much from Model 1 to the Model 2. More specifically, the relationships between motivation and negotiation and between negotiation and sport consumption are also very similar. However, Model 2 provides support for the existence of a negative effect of constraints on sport consumption $(\beta=-.257, p<.05)$. Moreover, team identification was found to significantly interact with constraints to affect sport consumption $(\beta=-.106, p<.05)$. Therefore, we find support for all hypotheses (hypotheses $1 \mathrm{~b}$ to $6 \mathrm{~b}$ ). Fair-weather fans were predicted to be less constrained, but instead, they are more constrained to consume sport when compared to die-hard fans. Model 2 is theoretically grounded and should be retained.

\section{Testing of Moderating Effects}

Even though Model 2 should be retained, we believe there are logical justifications for why further testing is needed. First, die-hard fans are personally attached to their favorite team, and-while being constrainedthey prioritize team support. Hence, we expect Model 2 is a better fit for die-hard fans. However, the same cannot be said about fair-weather fans. To further analyze the impact of team identification on the proposed models, we decided to separate fans into groups (die-hard vs fair-weather) through a median split for further analysis (Walker \& Kent, 2009). According to an independent $t$-test, die-hard fans were significantly more identified with their favorite sport team $(M$ (die-hard $)=4.67$ vs $M$ (fair-weather) $=2.66 ; t=-24.83, p<.05)$. Figure 3 shows SEM results across the two groups. A chisquare test indicated a statistically significant difference between models involving die-hard and fair-weather fans $\left(\chi_{(96)}^{2}\right.$ for unconstrained model $=224.421, \chi^{2}{ }_{(101)}$ for constrained model $=251.856$, and $\Delta \chi_{(5)}^{2}=27.44, p<$ .001 ), supporting the moderating effect of team identification. As seen in Figure 3, path coefficients between negotiation and sport consumption are positive and statistically significant for both die-hard and fair-weather fans ( $\beta=.64$ and $\beta=.66$, respectively). Results show support for the notion that die-hard fans consume sport in all aspects $(M$ (die-hard/attendance) $=15.05$ vs $M$ (fair-weather/attendance $)=9.53 ; t=-12.92, p<.001$; $M($ die-hard $/$ media $)=23.24$ vs $M$ (fair-weather $/$ media $)$ $=16.12 ; t=-13.18, p<.001 ; M$ (die-hard $/$ merchandise $)=7.20$ vs $M$ (fair-weather $/$ merchandise $)=4.78$; $t=-9.95, p<.001)$. Team identification significantly moderated the relationship between motivation and negotiation. As we predicted, fair-weather fans are more 


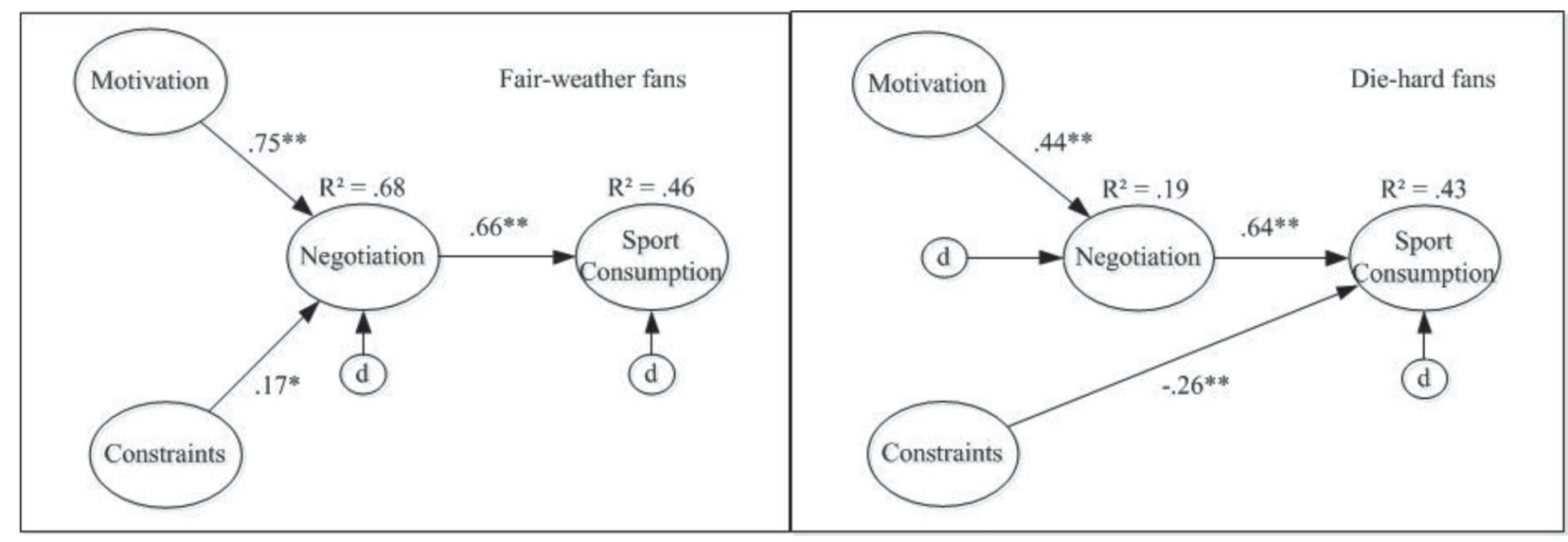

Figure 3. Structural models examining the relationships among constraints, motivation, negotiation, and sport consumption for die-hard fans and fair-weather fans. Note. ${ }^{*} p<.001,{ }^{\star} p<.005$

motivated to negotiate. However, we did not find team identification significantly moderated the relationship between constraints and negotiation for fair weather fans. Thus, no support was found for hypotheses $2 \mathrm{a}$ and $6 \mathrm{a}$. Although die-hard fans consumed more sports, we can still conclude that they were less likely to use negotiation to overcome constraints when compared to fair-weather fans. ${ }^{4}$

We found that negotiation mediates the relationship between constraints and sport consumption for fair-weather fans but not for die-hard fans. In fact, constraints decrease the consumption of sport for die-hard fans. Moreover, both die-hard and fair-weather fans are motivated to negotiate in order to consume sport as path coefficients were statistically significant. The path between motivation and negotiation for fair-weather fans $(\beta=.75, p<.05)$ was stronger than for die-hard fans $(\beta=.44, p<.05)$. To conclude, die-hard fans' behavior is in line with Model 2, whereas the behavior of fair-weather fans is better predicted by Model 1.

Overall, both models show that (a) fair-weather fans are more motivated to negotiate in order to consume sport, (b) negotiation plays a key role in explaining more variance in sport consumption, and (c) die-hard fans are less constrained to consumer sport $(\beta=-.106, p<.05)$. Table 2 describes paths with direction, predicted sign, and support for hypotheses for both Models 1 and 2.

\section{Test of Mediating Effects}

Through a mediating test, the following research questions were answered: Is negotiation a key mediator in the model of motivation, constraints, and sport consumption? What role does team identification play in

4 Constraints significantly decreased the consumption of sport for die-hard fans $(\beta=-.26, p<.05)$ but not for fairweather fans. the model when motivation, constraints, and negotiation are included?

Using bootstrapping, we find that negotiation mediates the relationship between constraints and sport consumption for fair-weather fans $\left(\beta_{\text {(constraints } \rightarrow \text { negotiation } \rightarrow \text { sport consumption) }}=.11, p<.05\right)$. However, the same is not true for die-hard fans $\left(\beta_{\text {(constraints } \rightarrow \text { negotiation } \rightarrow \text { sport consumption) }}=.05, p>.05\right)$. Negotiation is the most significant direct predictor of sport consumption $\left(\beta_{\text {(negotiation } \rightarrow \text { sport consumption })}=.65, p<.05\right)$. Further, constraints decrease sport consumption only for die-hard fans $\left(\beta_{\text {(constraints } \rightarrow \text { sport consumption) }}=-.22, p<.05\right)$ while negotiation mediates the relationship between motivation and sport consumption for both die-hard and fair-weather fans $\left(\beta_{\text {(motivation } \rightarrow \text { negotiation } \rightarrow \text { sport consumption) }}=.28, p<.05\right.$; and $\left(\beta_{\text {(motivation } \rightarrow \text { negotiation } \rightarrow \text { sport consumption })}=.51, p<.05\right.$, respectively $)$. Finally, the variables we included in the models explain about $46 \%$ to $43 \%$ of variance in sport consumption.

\section{Discussion}

\section{Does Negotiation Mediate Constraints and Motivation for Sport Consumption?}

Our results suggest that negotiation mediates the relationship between motivation and sport consumption for both die-hard and fair-weather fans. This is a significant contribution that applies previous work (Hubbard \& Mannell, 2001; Son, Mowen, Kerstetter et al., 2008) to sport marketing. By dividing fans into groups, we find that die-hard fans are less likely to use negotiation to overcome constraints. However, we also find that negotiation efforts outweigh the negative impact of constraints for fair-weather fans. It could be that negotiation is more likely to be a constraint mediator for fair-weather fans or that negotiation only mediates constraints for fair-weather fans during successful times. A way to eliminate such doubt is to conduct a 
Table 2. The Structural Equation Modeling Results

\begin{tabular}{|c|c|c|c|}
\hline Hypothesis & Path & Path Coefficient & Conclusion \\
\hline \multicolumn{4}{|c|}{ Direct Effects } \\
\hline H1a & Motivation $\rightarrow$ Negotiation & $0.620^{* *}$ & Supported \\
\hline $\mathrm{H} 2 \mathrm{a}$ & Constraints $\rightarrow$ Negotiation & 0.010 & Not Supported \\
\hline $\mathrm{H} 3 \mathrm{a}$ & Negotiation $\rightarrow$ Sport Consumption & $0.670^{* *}$ & Supported \\
\hline $\mathrm{H} 1 \mathrm{~b}$ & Motivation $\rightarrow$ Negotiation & $0.630^{* *}$ & Supported \\
\hline $\mathrm{H} 2 \mathrm{~b}$ & Constraints $\rightarrow$ Sport Consumption & $-0.260^{\star *}$ & Supported \\
\hline $\mathrm{H} 3 \mathrm{~b}$ & Negotiation $\rightarrow$ Sport Consumption & $0.710^{* *}$ & Supported \\
\hline \multicolumn{4}{|c|}{ Mediating Effects } \\
\hline $\mathrm{H} 4 \mathrm{a}$ & Motivation $\rightarrow$ Negotiation $\rightarrow$ Sport Consumption & $0.420^{\star *}$ & Supported \\
\hline $\mathrm{H} 4 \mathrm{a}$ & Constraints $\rightarrow$ Negotiation $\rightarrow$ Sport Consumption & 0.007 & Not Supported \\
\hline $\mathrm{H} 4 \mathrm{~b}$ & Motivation $\rightarrow$ Negotiation $\rightarrow$ Sport Consumption & $0.450^{* *}$ & Supported \\
\hline \multicolumn{4}{|c|}{ Moderating Effects } \\
\hline $\mathrm{H} 5 \mathrm{a}$ & $\begin{array}{l}\text { Team Identification moderates the relationship } \\
\text { between Motivation and Negotiation }\end{array}$ & $-0.250^{* *}$ & Supported \\
\hline H6a & $\begin{array}{l}\text { Team Identification moderates the relationship } \\
\text { between Constraints and Negotiation }\end{array}$ & -0.070 & Not Supported \\
\hline $\mathrm{H} 5 \mathrm{~b}$ & $\begin{array}{l}\text { Team Identification moderates the relationship } \\
\text { between Motivation and Negotiation }\end{array}$ & $-0.270^{* *}$ & Supported \\
\hline $\mathrm{H} 6 \mathrm{~b}$ & $\begin{array}{l}\text { Team Identification moderates the relationship } \\
\text { between Constraints and Sport Consumption }\end{array}$ & $-0.110^{* *}$ & Not Supported \\
\hline
\end{tabular}

longitudinal study including data on teams with unsuccessful, successful, and average past seasons.

Sport marketers can use our findings to explore consumption campaigns that incentivize negotiation through fan attachment during good times. To boost consumption for fair-weather fans, for example, they can offer a limited amount of tickets at the end of a successful season that, if purchased, would award fans an opportunity to either meet coaches or key players and receive an autographed football. Another example is to launch campaigns soon after major upsets occur (e.g., soon after the focal team upsets a higher ranked opponent), which are likely to apply for both die-hard and fair-weather fans. Here, those purchasing a certain type of licensed merchandise in a fixed period of time (maybe a 24-hour window immediately after the upset) automatically enter a lottery to win a chance to visit the next team practice. Finally, another way to incentivize fans to consume via negotiation is to offer licensed merchandise discounts on games soon after rivalry wins. These can be launched in bundles with stadium tickets and media, for example.

In conclusion, our study confirms and extends previous research findings by providing researchers and practitioners with a better understanding of fluctuations in sport consumption based on motivation, negotiation, constraints, and team identification. Particularly, our study contributes to theory by introducing team identification and negotiation to an adapted constraints-effects-mitigation model to better explain sport consumption behavior.

\section{Is There a Team Identification Moderating Effect?}

The results support our theory that fans' identification levels moderate their sport consumption through motivation, constraints, and negotiation. The results also support the hypothesis that fair-weather fans are more motivated and therefore negotiate more constraints in order to consume sport. Given the nature of our data, we believe this is associated with fair-weather fans overly showing support during good times as a way to compensate for the lack of support during bad times. The results also indicate that fair-weather fans are more constrained than die-hard fans. This finding is unexpected but could be explained by the possibility that fair-weather fans may feel the need to negotiate constraints to provide support for their favorite team during good times in order to compensate for their non-support during bad times. Die-hard fans might not feel this need to negotiate constraints given their loyalty and consistent support. As mentioned in the methods section, the team under investigation had the 
third best record standing in its conference, playing for a championship game for the first time in six years. Therefore, it appears that fans responded to questions related to sport consumption during a successful year. If the examination had investigated a disastrous season, results may have been different. Surprisingly, die-hard fans did not negotiate imposed constraints at all. We believe that die-hard fans either (a) used a strategy other than negotiation to overcome constraints or (b) ignored constraints and consumed anyway.

One of the theoretical contributions of the current study is that it includes team identification as a moderator when examining the relationships among motivation, negotiation, constraints, and sport consumption. Otherwise, research may lead to biased results. For instance, if we had not divided fans into two groups, we would not have discovered that constraints had a significant relationship with negotiation for fair-weather fans but only a direct negative effect on sport consumption. If we had not examined the effects of team identification as a moderator, we would have only retained Model 2, and no further conclusions would have been made. For example, we would not have known that diehard fans did not negotiate constraints and behaved as predicted by Model 2. Furthermore, we would not have known that fair-weather fans used negotiation strategies to consume sport, following predictions made by Model 1. Based on the findings, we suggest that sport marketers realize that team identification does influence the behavior of fans (Wann \& Branscombe, 1993). In good times, we suggest that sport marketers should focus on fair-weather fans and attempt to gain their loyalty as these fans are more "vulnerable" during successful seasons and may be more willing to do whatever it takes to show support, which would increase self-esteem (Tajfel \& Turner, 1985). Hence, offering discounts on next season's tickets might be a way to start building longterm successful relationships with fair-weather fans. On the other hand, it seems that current promotions do not incentivize die-hard fans to negotiate constraints. Thus, we suggest that sport marketers develop new products/ services that motivate die-hard fans, such as attend all of your favorite team's home games and enter a chance to win autographed jerseys from coaches and players.

\section{Limitations and Future Research Suggestions}

Our study has several limitations that should be acknowledged. First, we analyzed consumers of college (American) football. Although intercollegiate athletics in the United States is a lucrative industry and resembles professional sport in many ways, thus providing a basis for generalizability to other spectator sport products, future studies should examine the models developed in this study with other spectator sports and with different populations of sport spectators. In addition, we should acknowledge that our study was conducted in North America, and therefore the results are not generalizable across cultures and systems.

Second, we used composite scores to estimate the models, but future studies might want to consider the use of multi-item scores to investigate more specific relationships. For example, we advise scholars to use multi-item scores when examining the relative effect of individual motivation (e.g., team achievement) and constraint factors (e.g., structural constraint) on sport consumption (e.g., attendance) through a negotiation factor (e.g., time management) for die-hard fans. Our data, besides being cross-sectional, involved fans of a college football team that had a successful past season, and so we advise researchers to use the same models when investigating a longitudinal study where several teams with different season outcomes are included. It is expected that die-hard fans would respond similarly, yet the same could not be said about fair-weather fans because past research has blamed them for fluctuations in sport consumption (Murrell \& Dietz, 1992). Lastly, it might be interesting to examine the moderating effect of sociodemographic variables (e.g., gender and income) on the current model to examine if the model would function differently according to various sociodemographic variables (Son, Mowen, Kerstetter et al., 2008). In addition, relationships within the hypothesized models (i.e., motive/constraints-negotiation-sport consumption) may function variably according to various situational moderators. These may include but are not limited to team performance (e.g., winning vs losing), level of competition (e.g., major league vs minor league), weather, and scheduling (weekday vs weekend). Further testing with the inclusion of the various situational and personal moderators would enable researchers and practitioners to better understand not only how motivation/constraints and negotiation function together to explain sport consumption but also under which condition(s) the proposed relationships would hold and change.

\section{References}

Alexandris, K., Funk, D. C., \& Pritchard, M. (2011). The impact of constraints on motivation, activity attachment, and skier intentions to continue. Journal of Leisure Research, 43, 56-79.

Armstrong, J. S., \& Overton, T. S. (1977). Estimating nonresponse bias in mail surveys. Journal of Marketing Research, 14, 396-402.

Bodet, G., \& Bernache-Assolant, L. (2011). Consumer loyalty in sport spectatorship services: The relationships with consumer satisfaction and team identification. Psychology and Marketing, $28,781-802$.

Byrne, B. N. (2009). Structural equation modeling with AMOS (2nd ed.). Lawrence Erlbaum Associates. 
Carroll, B., \& Alexandris, K. (1997). Perception of constraints and strength of motivation: Their relationship to recreational sport participation in Greece. Journal of Leisure Research, 29, 279-299.

Crawford, D. W., Jackson, E. L., \& Godbey, G. (1991). A hierarchical model of leisure constraints. Leisure Sciences, 13, 309-320.

Drakou, A., Tzetzis, G., \& Mamantzi, K. (2008). Leisure constraints experienced by university students in Greece. Sport Journal, 11(1), 55-64.

Fink, J. S., Trail, G. T., \& Anderson, D. F. (2002). An examination of team identification: Which motives are most salient to its existence? International Sports Journal, 6, 195-207.

Fornell, C., \& Larcker, D. F. (1981). Evaluating structural equation models with unobservable variables and measurement error. Journal of Marketing Research, 18, 39-50.

Funk, D. C., \& James, J. D. (2006). Consumer loyalty: The meaning of attachment in the development of sport team allegiance. Journal of Sport Management, 20, 189-217.

Hair, J. F., Black, W. C., Babin, B. J., \& Anderson, R. E. (2010). Multivariate data analysis (7th ed.). Prentice Hall.

Hancock, G. R., \& Nevitt, J. (1999). Bootstrapping and the identification of exogenous latent variables within structural equation models. Structural Equation Modeling, 6, 394-399.

Harris, D. V. (1973). Involvement in sport: A somatopsychic rationale for physical activity. Lea \& Febiger.

Hershberger, S. L. (2004). The problem of equivalent structural models. In A second course in structural equation modeling. Information Age Publishing.

Hubbard, J., \& Mannell, R. C. (2001). Testing competing models of the leisure constraint negotiation process in a corporate employee recreation setting. Leisure Sciences, 23, 145-163.

Jackson, E. L., Crawford, D. W., \& Godbey, G. (1993). Negotiation of leisure constraints. Leisure Sciences, 15, 1-11.

Jones, C. W., Byon, K. K., \& Mowatt, R. A. (2017). The balance proposition: How strength of motivation moderates the relationship between constraints and attendance intentions. International Journal of Sport Management, 18, 516-545.

Jun, J., \& Kyle, G. T. (2011). The effect of identity conflict/facilitation on the experience of constraints to leisure and constraint negotiation. Journal of Leisure Research, 43, 176-204.

Kim, Y. K., \& Trail, G. (2010). Constraints and motivators: A new model to explain sport consumer behavior. Journal of Sport Management, 24, 190-210.

Kim, Y. K., \& Trail, G. (2011). A conceptual framework for understanding relationships between sport consumers and sport organizations: A relationship quality approach. Journal of Sport Management, 25, 57-69.

Kim, Y. K., Trail, G., \& Ko, Y. J. (2011). The influence of relationship quality on sport consumption behaviors: An empirical examination of the relationship quality framework. Journal of Sport Management, 25, 576-592.
Loucks-Atkinson, A., \& Mannell, R. C. (2007). Role of self-efficacy in the constraints negotiation process: The case of individual with fibromyalgia syndrome. Leisure Sciences, 29, 19-36. http:// dx.doi.org/10.1080/01490400600983313

Mardia, K. V. (1970). Measures of multivariate skewness and kurtosis with applications. Biometrika, 57, 519-530.

Murrell, A. J., \& Dietz, B. (1992). Fan support of sport teams: The effect of a common group identity. Journal of Sport \& Exercise Psychology, 14, 28-39.

Nunnally, J. C. (1978). Psychometric theory (2nd ed.). McGraw-Hill.

Petrick, J. T., Backman, S. J., Bixler, R., \& Norman, W. C. (2001). Analysis of golfer motivations and constraints by experience use history. Journal of Leisure Research, 33, 56-70.

Sloan, L.R. (1989). The motives of sports fans. In J. H. Goldstein (Ed.), Sports, games, and play: Social \& psychological viewpoints (2nd ed., pp. 175-240). Lawrence Erlbaum Associates.

Son, J. S., Kerstetter, D. L., \& Mowen, A. J. (2008). Do age and gender matter in the constraint negotiation of physically active leisure? Journal of Leisure Research, 40, 267-289.

Son, J. S., Mowen, A. J., \& Kerstetter, D. L. (2008). Testing alternative leisure constraint negotiation models: An extension of Hubbard and Mannell's study. Leisure Sciences, 30, 198-216.

Tajfel, H., \& Turner, J. C. (1985). The social identity theory of group behavior. In H. Tajfel (Ed.), The social dimension: European developments in social psychology (pp. 15-40). Cambridge University Press.

Trail, G. T., \& James, J. D. (2001). The motivation scale for sport consumption: Assessment of the scale's psychometric properties. Journal of Sport Behavior, 24, 108-127.

Trail, G. T., \& James, J. D. (2012). Sport consumer behavior. Sport Consumer Research Consultants LLC.

Trail, G. T., \& Kim, Y. K. (2011). Factors influencing spectator sports consumption: NCAA women's college basketball. International Journal of Sports Marketing \& Sponsorship, 13, 60-82.

Vandenberg, R. J., \& Grelle, D. M. (2009). Alternative model specifications in structural equation modeling: Facts, fictions, and truth. In C. E. Lance \& R. J. Vandenberg (Eds.), Statistical and methodological myths and urban legends: Doctrine, verity and fable in the organizational and social sciences (pp. 165-191). Routledge/Taylor \& Francis Group.

Walker, M., \& Kent, A. (2009). Do fans care? Assessing the influence of corporate social responsibility on consumer attitudes in the sport industry. Journal of Sport Management, 23, 743-769.

Wann, D. L., \& Branscombe, N. R. (1993). Sports fans: Measuring degree of identification with their team. International Journal of Sport Psychology, 24, 1-17.

White, D. D. (2008). A structural model of leisure constraints negotiation in outdoor recreation. Leisure Sciences, 30, 342-359. 
Past Sport Consumption (5-point Likert)

(Kim, Trail, \& Ko, 2011)
1. How many times did you attend a Team Name home football game?

2. How many times did you attend a Team Name away football game?

3. How many times did you watch a televised Team Name football game?

4. How many times per week did you access the Team Name official website for information regarding football?

5. How many times per week did you access other websites (e.g., ESPN) for information regarding Team Name football?

6. How many times per week did you purchase Team Name licensed merchandise products?

Future Sport Consumption (5-point Likert)

7. How likely will you attend home games?

(Kim, Trail, \& Ko, 2011)

8. How likely will you attend away games?

9. How likely will you watch televised games?

10. How likely will you weekly access the Team Name official website for information regarding football?

11. How likely will you weekly access other websites (e.g., ESPN) for information regarding Team Name football?

12. How likely will you weekly purchase Team Name licensed merchandise products?

Team Identification
(1= Not at all,
$2=$ Little,
$3=$ Moderate,
$4=$ Lot,
$5=$ Very much)
(Trail \& James, 2001;
Wann \& Branscombe, 1993)

Past Constraints to Home

Attendance

(5-point Likert)

13. How important is it to you that the Team Name football team wins?

14. How strongly do you see yourself as a fan of the Team Name football team?

15. How important is being a fan of Team Name football?

16. How often do you brag about Team Name football team at work, at your house, or on your clothing?

17. Do you feel badly when the Team Name football team loses?

(Hubbard \& Mannell, 2001) 21. I didn't have friends to go to games with.

18. I was too shy so I preferred to not attend games.

19. I didn't have the energy to attend games.

20. I didn't feel comfortable attending games.

22. People with whom I would go to games with were on different work schedules.

23. The people I know lived far away.

24. Students' season tickets were too expensive.

25. Single game tickets were too expensive.

26. I did not get the student tickets for the games I wanted.

27. I was too busy with academic workload.

Past Constraints to Away

Attendance

(5-point Likert)

28. I was too shy so I preferred to not travel

29. I didn't have the energy to travel for the games

30. I didn't feel comfortable attending away games.

(Hubbard \& Mannell, 2001) 31. I didn't have friends to travel with.

32. People with whom I would travel with were on different work schedules.

33. The people I know didn't want to travel away.

34. The people I know couldn't travel because they were busy with academic workload.

35. I didn't have the time to travel.

36. Away games' tickets were too expensive.

37. The travel was going to be too expensive.

Past Constraints to Media 38. I usually had other plans.

Usage

(5-point Likert)

39. I did have time but no interest.

(Hubbard \& Mannell, 2001) 41. People with whom I would watch games with were on different work schedules.

42. Cable TV was too expensive.

43. It was too expensive to watch games online.

44. Game times conflicted with other regularly scheduled activities to which I had committed.

45. Game times conflicted with other TV programs that I regularly watch.

46. Game times conflicted with my studying schedule.

Past Constraints to the

Purchase of Licensed

Merchandise

(5-point Likert)

(Hubbard \& Mannell, 2001)
47. I was too shy to go buy products by myself.

48. I didn't have the energy to go to stores buy Team Name gear.

49. I didn't feel comfortable wearing Team Name clothing.

50. I didn't have friends to purchase products with.

51. People with whom I would buy Team Name licensed merchandise with never had time to shop.

52. The people I know didn't want to shop Team Name gear.

53. I didn't have the time to shop.

54. Team Name clothing were too expensive.

55. Everything I wanted to buy was too expensive. 
Appendix. Scale Items Used in the Current Study (Continued)

Negotiation (Time

Management)

(5-point Likert)

(Hubbard \& Mannell, 2001)
56. Plan the trip long before the game.

57. Arrange places to watch the game.

58. Get to places ahead of time to save seats.

59. Be at a place with great Wi-Fi signal to watch it online.

60. Motivate myself to shop alone.

61. Search for Team Name clothing that fits my style.

62. Look for products on sale.

Negotiation (Interpersonal

Coordination)

(5-point Likert)

(Hubbard \& Mannell, 2001) 66. Meet other Georgia fans that were traveling to same games.

67. Persuade friends to come with me.

68. Find friend to shop with.

69. Identify people with same interests.

70. Persuade significant others to come with me.

Negotiation (Financial

Management)

(5-point Likert)

71. Save money for the trip.

72. Buy tickets ahead of time.

73. Save money for shopping.

(Hubbard \& Mannell, 2001) 74. Budget my money.

75. Get my parents to go shopping with me.

Motivation

(5-point Likert)

(Kim \& Trail, 2010)
76. The Team Name football team was awarded a great preseason ranking.

77. Team Name football game provided me with an opportunity to escape the reality of my daily life

78. Team Name football games were supposed to be close.

79. The Team Name football team was nationally ranked.

80. Team Name football games helped me to get away from the tension in my life.

81. The Team Name football games' outcomes were never certain.

82. The Team Name football team was expected to do well in the SEC conference.

83. Team Name football games helped me to distract myself and have a good time.

84. Team Name football games were expected to be dramatic 
Copyright of Sport Marketing Quarterly is the property of Fitness Information Technology, Inc. and its content may not be copied or emailed to multiple sites or posted to a listserv without the copyright holder's express written permission. However, users may print, download, or email articles for individual use. 